Article

\title{
Research on the Lightning Intruding Overvoltage and Protection Measures of 500 kV AC Fault Current Limiter
}

\author{
Changfu Chen ${ }^{1}$, Yongxia Han ${ }^{1, *} \mathbb{0}$, Junxiang Liu ${ }^{2}$, Wenxiong $\mathrm{Mo}^{2}$, Zhao Yuan ${ }^{3}$, \\ Jianning Huang ${ }^{1}$, Haibo $\mathrm{Su}^{2}$, Xiancong Zhang ${ }^{2}$ and Kaijian $\mathrm{Wu}^{3}$ \\ 1 School of Electric Power, South China University of Technology, Guangzhou 510641, China; \\ ccfl20131026@163.com (C.C.); huangjianning007@163.com (J.H.) \\ 2 Test \& Research Institute of Guangzhou Power Supply Co., Ltd., Guangzhou 514010, China; \\ jxliu_2006@126.com (J.L.); 841294180@163.com (W.M.); a771062947@163.com (H.S.); rexivan@163.com (X.Z.) \\ 3 School of Electrical and Electronic Engineering, Huazhong University of Science and Technology, \\ Wuhan 430074, China; Yuanzhao8507@163.com (Z.Y.); wukaijian2010@gmail.com (K.W.) \\ * Correspondence: epyxhan@scut.edu.cn
}

Received: 9 September 2019; Accepted: 8 October 2019; Published: 11 October 2019

\begin{abstract}
As one of the key technologies to solve the problem of high short-circuit current, the fault current limiter (FCL) has become a research hotspot in China and abroad. The overvoltage and protection measures of the FCL are the key technologies for its application. Therefore, this paper studies the lightning intruding overvoltage and protection measures for a $500 \mathrm{kV}$ FCL based on a high coupled split reactor (HCSR). Firstly, according to the main topology of the system and the $500 \mathrm{kV}$ HCSR-FCL structure, the lightning intruding overvoltage simulation model of the $500 \mathrm{kV}$ station, including the nearby transmission lines, is established on the PSCAD (Power Systems Computer Aided Design) program. Secondly, the lightning overvoltage of the equipment in the station and the components of the HCSR-FCL are simulated and analyzed when the transmission lines nearby are subjected to lightning shielding failure and back flashover. Meanwhile, the influence of the HCSR-FCL on the lightning overvoltage of the equipment in the station are compared and analyzed before and after the HCSR-FCL is installed. The simulation results show that the overvoltage of the equipment in the station and the components of the HCSR-FCL is more serious when the shielding failure occurs in the transmission lines nearby. The HCSR-FCL can reduce the lightning overvoltage of the equipment in the station, but the maximum inter-terminal and inter-arm lightning overvoltage of the HCSR can reach $1064 \mathrm{kV}$ and $790 \mathrm{kV}$, respectively, under the current limiting state and the current sharing state. Finally, methods of increasing the arresters on the transmission lines side of the HCSR-FCL and shunt capacitor between each module of the HCSR-FCL are proposed to reduce the lightning overvoltage. The lightning impulse withstand voltage of each component of the HCSR is also proposed: The inter-terminal lightning impulse withstand voltage of HCSR is $170 \mathrm{kV}$. The inter-arm lightning impulse withstand voltage of HCSR is $200 \mathrm{kV}$. The terminal-to-ground lightning impulse withstand voltage of the HCSR-FCL is $1550 \mathrm{kV}$.
\end{abstract}

Keywords: fault current limiter; overvoltage; high coupled split reactor; shunt capacitor; lightning impulse withstand voltage

\section{Introduction}

The short-circuit fault current of the $500 \mathrm{kV}$ power grid is becoming higher due to the increase of power grid capacity and density [1,2]. Traditional current-limiting methods will reduce the security 
margin and reliability of the power grid and endanger the safe and stable operation of the power grid [3].

As one of the effective measures to limit the short-circuit current, the fault current limiter (FCL) has been widely considered by researchers. At present, superconducting FCL, power electronic FCL, and economical FCL based on conventional equipment are the research hotspots [4-7]. However, superconducting FCL is expensive [8]. Power electronics FCL need complex bypass devices and a large space; hence, they cannot be widely used in a $500 \mathrm{kV}$ AC power grid [9]. The FCL based on a high coupled split reactor (HCSR) has become an important choice to limit the short-circuit current in a power grid due to its high technical and economic efficiency. The HCSR consists of two reverse coupled inductors, and the two reverse coupled inductors show low reactance when the power grid system is in a normal operation mode, during which the HCSR is working in a current sharing state. When a short-circuit fault occurs in the power grid system, the circuit breaker of one arm in the HCSR breaks, and the HCSR presents a high reactance, during which the HCSR is working in a current limiting state [10]. At present, research on HCSR is carried out on the theory, design, insulation, and current sharing in China and abroad [11-15]. HCSR-FCL research and engineering demonstration applications were also carried out for $220 \mathrm{kV}$ power grids in China [16]. However, as the short-circuit fault current of the $500 \mathrm{kV}$ power system is much higher than that of $220 \mathrm{kV}$ power system and the design structure of the $500 \mathrm{kV}$ HCSR and the $220 \mathrm{kV}$ HCSR are different, there are many practical problems in $500 \mathrm{kV}$ HCSR-FCLs to be solved for their application, such as current limiting depth, insulation design, and coordination with $500 \mathrm{kV}$ power grid equipment. Therefore, as the first application of the $500 \mathrm{kV}$ HCSR-FCL used in the $500 \mathrm{kV}$ power grid, it is necessary to study the influence of the HCSR-FCL on the lightning overvoltage and insulation coordination of the original $500 \mathrm{kV}$ system equipment and to propose the lighting impulse withstand voltage of the HCSR-FCL.

This paper aims to study the influence on other equipment in the $500 \mathrm{kV}$ power grid when the incoming transmission lines are subjected to lightning shielding failure and back flashover after a $500 \mathrm{kV}$ HCSR-FCL connects to a $500 \mathrm{kV}$ power grid. Furthermore, the lightning overvoltage of each component of the HCSR-FCL are studied under different working conditions, and protection measures are proposed. Finally, the lightning impulse withstand voltages of the HCSR-FCLs are proposed when the HCSR-FCL is applied in a demonstration project.

\section{The Topology and Parameters of the $500 \mathrm{kV}$ Power System}

The main topology of a $500 \mathrm{kV}$ power system to be connected with a $500 \mathrm{kV}$ HCSR-FCL is shown in Figure 1, in which the HCSR-FCL will be installed on the side of the Shunde-Guangnan transmission line near Guangnan station. Considering the future development of the power grid and the requirement of the current limiting ratio, the inductance of one arm of each module is $4.1 \mathrm{mH}$, the coupling coefficient is 0.977 , and topology of the HCSR-FCL is shown in Figure 2. The HCSR-FCL consists of two identical modules, and each module includes one HCSR, four voltage-equalizing capacitors, four fast switches, and their stray capacitors to the ground. Among them, $\mathrm{C} 1$ is a voltage-equalizing capacitor, and $\mathrm{C} 2$ and $\mathrm{C} 3$ are stray capacitors to the ground of the fast switches. The parameters of $\mathrm{C} 1, \mathrm{C} 2$, and $\mathrm{C} 3$ are shown in Table 1. 


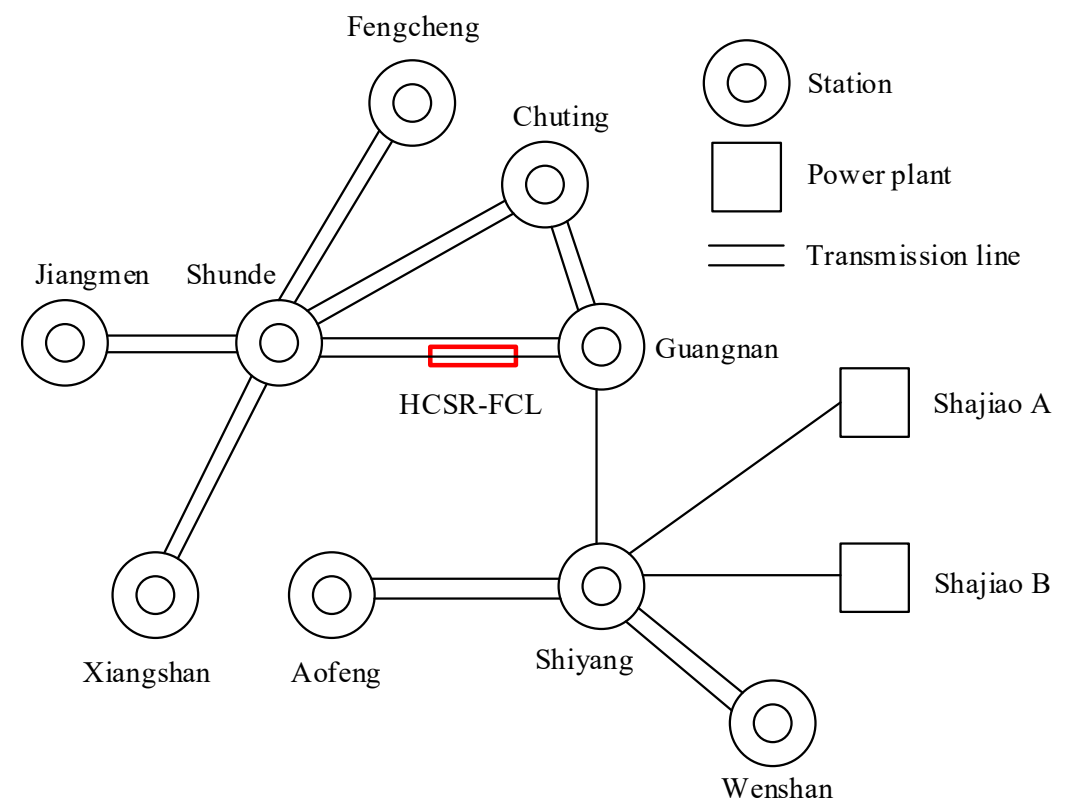

Figure 1. Topology of the $500 \mathrm{kV}$ power system.

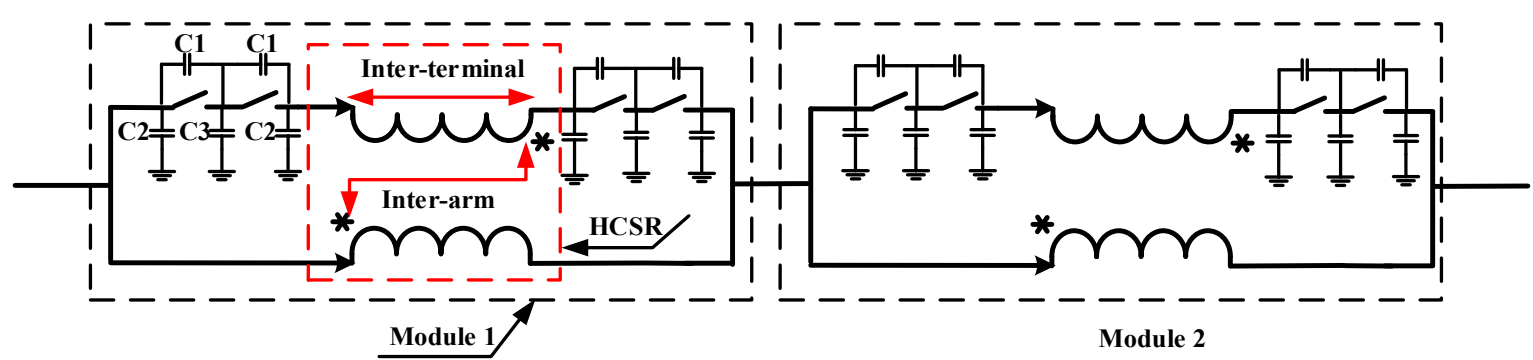

Figure 2. Topology of the high coupled split reactor fault current limiter (HCSR-FCL).

Table 1. Parameters of the capacitors.

\begin{tabular}{cccc}
\hline Device & $\mathrm{C} 1 / \mathrm{pF}$ & $\mathrm{C} 2 / \mathrm{pF}$ & $\mathrm{C} 3 / \mathrm{pF}$ \\
\hline Capacitor & 1000 & 40 & 100 \\
\hline
\end{tabular}

The working principles of the HCSR-FCL are as follows: When the power system is in normal operation, the eight fast switches are closed, and the HCSR-FCL is in the current sharing state; when a fault occurs, the eight fast switches are disconnected, and the HCSR-FCL is in the current limiting state. Therefore, it is necessary to separately analyze the lightning overvoltage of each component of the HCSR-FCL under the states of current sharing and current limiting after the HCSR-FCL is connected to the $500 \mathrm{kV}$ power system.

\section{Implementation Cost of the HCSR-FCL}

The HCSR-FCL consists of two HCSRs, eight fast switches, their voltage-equalizing capacitors, and matching equipment in its practical application. The costs of each part of the HCSR-FCL which have been stated by the consulted equipment manufacturers are shown in Table 2 . The costs of other types of FCLs and the HCSR-FCL are shown in Table 3. 
Table 2. Cost of the HCSR-FCL.

\begin{tabular}{cccc}
\hline Device & Cost $/ \mathbf{\$}$ & $\begin{array}{c}\text { Total Cost of Single-Phase } \\
\text { HCSR-FCL/\$ }\end{array}$ & $\begin{array}{c}\text { Total Cost of Three-Phase } \\
\text { HCSR-FCL/\$ }\end{array}$ \\
\hline $\begin{array}{c}\text { Two HCSR } \\
\begin{array}{c}\text { Eight fast switches and their } \\
\text { voltage-equalizing capacitors } \\
\text { Matching equipment }\end{array}\end{array}$ & 360,000 & & $1,830,000$ \\
\hline
\end{tabular}

Table 3. Costs of the FCLs.

\begin{tabular}{cccc}
\hline Device & HCSR-FCL & Series-Resonant FCL & Superconducting FCL \\
\hline Cost $/ \$$ & $1,830,000$ & $11,400,000$ & over $14,300,000$ \\
\hline
\end{tabular}

Compared with other type FCLs, the cost of the HCSR-FCL is much lower. Furthermore, one branch of the HCSR-FCL only flows through half of the short-circuit current when a short-circuit fault occurs, so that common equipment can be adopted as maintenance equipment, and maintenance is simple, which can also reduce the cost of the HCSR-FCL in practical engineering.

\section{Modeling Methods}

\subsection{Lightning Parameters}

\subsubsection{Lightning Current Waveform}

The lightning current waveform is simulated by a $2.6 / 50 \mu$ s double exponential wave. The impedance of the lightning current channel is related to the magnitude of lightning current [17], and therefore, the impedance of the lightning current channels is selected to be $300 \Omega$ and $800 \Omega$, respectively, during back flashover and shielding failure.

\subsubsection{Lightning Point}

It is supposed that the lightning strikes on the nearest six towers of Guangnan station. The back flashover and shielding failure of the incoming transmission lines will cause the intruding overvoltage to the station.

\subsubsection{Lightning Current Amplitude}

The lightning withstand level of back flashover and shielding failure is calculated by the simulation, and the maximum shielding current is calculated by electrical geometry model [18]. In the subsequent simulations, the magnitude of lightning current of back flashover and shielding failure is considered comprehensively.

\subsection{Line Model}

The length of the transmission line from Guangnan station to Shunde station is $67 \mathrm{~km}$. The conductor adopts a four-split structure. The conductor type is JNRLH60X/LB14-350/35, the splitting distance and the DC resistance of the conductor are $450 \mathrm{~mm}$ and $0.0818 \Omega / \mathrm{km}$, respectively. The overhead ground line is in JLB40-150 type, and the DC resistance is $0.2952 \Omega / \mathrm{km}$. A frequency-dependent (phase) model of the transmission lines is used in the PSCAD program. This paper does not consider the effect of corona on the lightning intruding overvoltage. 


\subsection{Tower Model}

The tower model adopts the multi-conductor layered wave impedance model proposed by Yamada and Hara $[19,20]$. The model takes into account the variation of tower parameters with height, and also includes the propagation characteristics of wave on tower and cross-arm. In this paper, the parameters of the tower are shown in Table 4, and the multi-wave impedance model of the tower is shown in Figure 3.

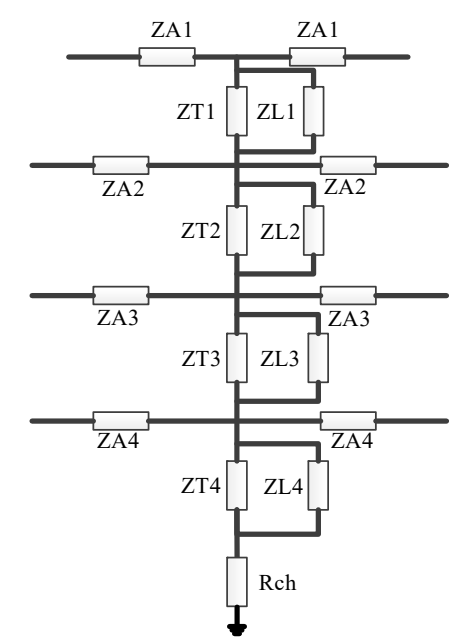

Figure 3. Multi-wave impedance model of transmission tower.

Table 4. Parameters of the towers.

\begin{tabular}{cccc}
\hline Tower Number & Tower Type & Span/m & Gap Distance/m \\
\hline$\# 1$ & SJCD344-30 & 342 & 4.3 \\
$\# 2$ & SJC343-33 & 289 & 4.3 \\
$\# 3$ & SZC344-56 & 334 & 3.7 \\
$\# 4$ & SZC343-36 & 287 & 3.7 \\
$\# 5$ & SZC341-31 & 272 & 3.7 \\
$\# 6$ & SJC341-21 & 242 & 4.3 \\
\hline
\end{tabular}

\subsection{Insulator String Flashover Criterion}

The FXBW-500/240D insulator is used in Guangnan station. The ideal controllable switch is used to model the insulator. The leader propagation method is chosen as the flashover criterion of the insulators, and the leader velocity adopts the equation proposed by CIGRE Working Group [21]. The gap distance of the flashover criterion is shown in Table 4 .

\subsection{Equipment Model of The Station}

Because of the high equivalent frequency of lightning intruding overvoltage, the equipment in the station, such as the transformers, disconnectors, circuit breakers, hybrid gas insulated switchgear bushings, etc., can be equivalent to the impulse capacitor [22-25]. There are distributed parameter lines between them. The equivalent capacitance of some equipment is shown in Table 5 . The equivalent circuit of the station connected with the HCSR-FCL is shown in Figure 4. TR1 is main transformer, CVT is capacitive voltage transformer, HGIS bushing is hybrid gas insulated switchgear bushing, DS is disconnector, $\mathrm{CT}$ is current transformer, $\mathrm{CB}$ is circuit breaker, and MOA is metal oxide arrester. The arrester type near the main transformer in the station is Y20W1-420/1046 (MOA1) and the arrester type near the incoming line is Y20W1-444/1063 (MOA2). The single-column measured U-I characteristics of the arresters are shown in Table 6. Appendix A shows how to study the lightning overvoltage and insulation design of the HCSR-FCL when the HCSR-FCL is applied to a station. 
Table 5. Equivalent capacitor of some equipment.

\begin{tabular}{cccccc}
\hline Device & TR1/pF & CVT/pF & DS/pF & CT/pF & HGIS Bushing/pF \\
\hline Capacitor & 5000 & 5000 & 150 & 1000 & 200 \\
\hline
\end{tabular}

Table 6. U-I characteristics of the arresters.

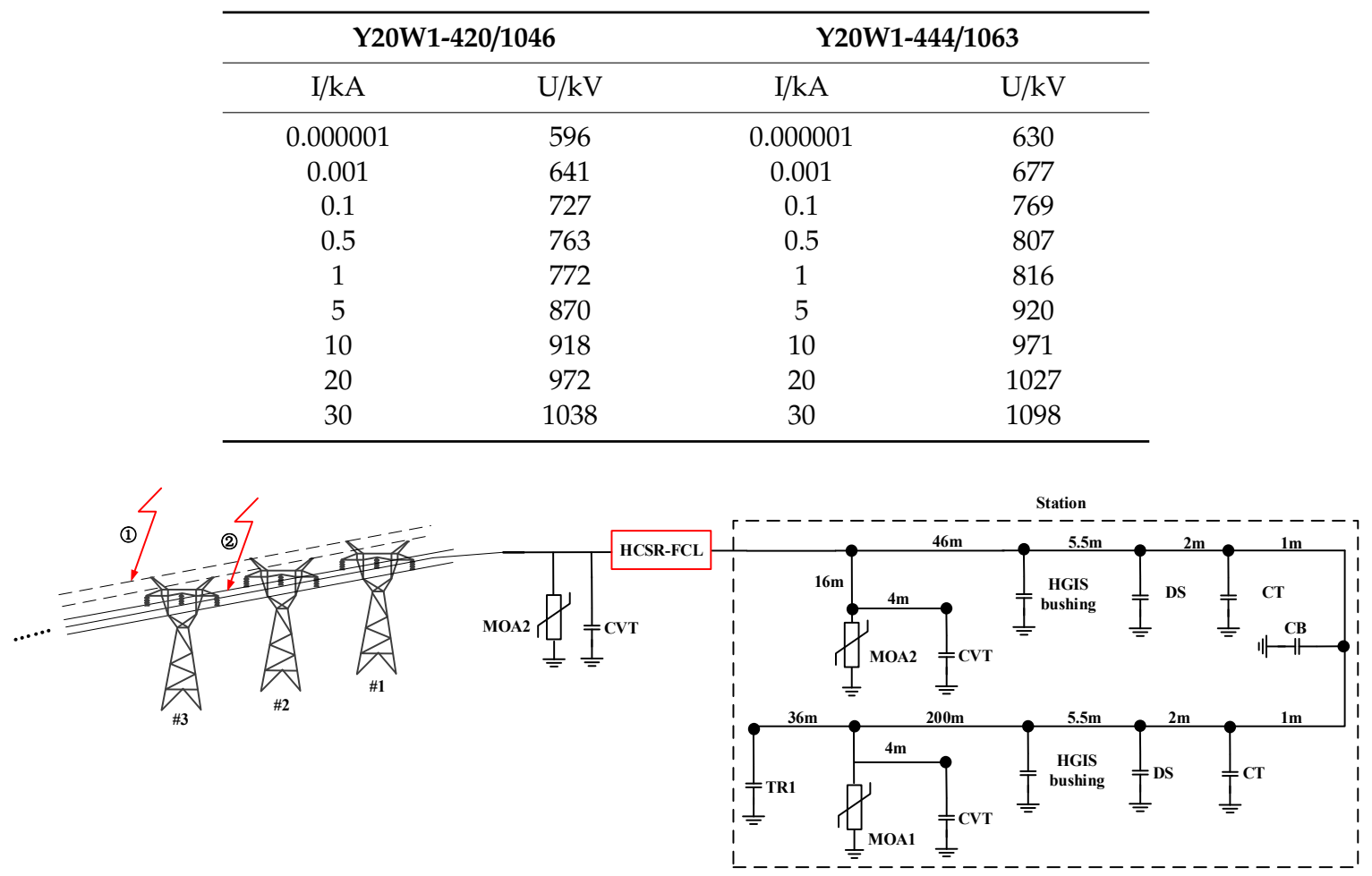

Figure 4. Equivalent circuit of $500 \mathrm{kV}$ Guangnan station connected with the HCSR-FCL.

\section{Simulation Results and Analysis}

According to the above modeling method, a simulation model for lightning intruding overvoltage of the $500 \mathrm{kV}$ HCSR-FCL is established in the PSCAD/EMTDC program, and the simulation step is $0.002 \mu \mathrm{s}$.

\subsection{Back Flashover}

In order to improve the reliability of the equipment, this paper calculates the lightning intruding overvoltage based on the once-in-a-century lightning current. According to the cumulative probability distribution of lightning current amplitude and the ground lightning density in Guangdong Province from 2008 to 2017, the amplitude of the once-in-a-century lightning current of the incoming line can be calculated. The calculation method is shown in Equation (1).

$$
L \times N_{\mathrm{L}} \times P=\frac{1}{100}
$$

where $L$ is the length of the incoming line, $\mathrm{km} ; N_{\mathrm{L}}$ is the flashes $/ 100 \mathrm{~km} / \mathrm{a} ; P$ is the cumulative probability distribution function of lightning current amplitude. $N_{\mathrm{L}}$ and $P$ are calculated by Equations (2) and (3), respectively.

$$
\begin{aligned}
& N_{\mathrm{L}}=N_{\mathrm{g}}\left(\frac{28 h^{0.6}+d}{10}\right) \\
& P(i \geq I)=\frac{1}{1+(I / a)^{b}}
\end{aligned}
$$


where $N_{\mathrm{g}}$ is the ground flash density (GFD), which takes 8.13 flashes $/ \mathrm{km}^{2} / \mathrm{a} ; h$ is the tower height, which takes $56 \mathrm{~m} ; d$ is the overhead ground wire (OHGW) separation distance, which takes $15 \mathrm{~m}$; $a=28.96$; and $b=3.4$.

From Equations (1)-(3), the lightning current amplitude of the incoming transmission lines that may be struck once in a hundred years is $177 \mathrm{kA}$.

The lightning voltage across the insulator was simulated and analyzed when the incoming transmission lines caused the lightning back flashover and shielding failure, and Figure 5 shows the typical lightning voltage across the insulator. In order to analyze the influence of the HCSR-FCL on the overvoltage of the equipment in the station, the overvoltage of the equipment in the station were analyzed with the HCSR-FCL connected and not connected.

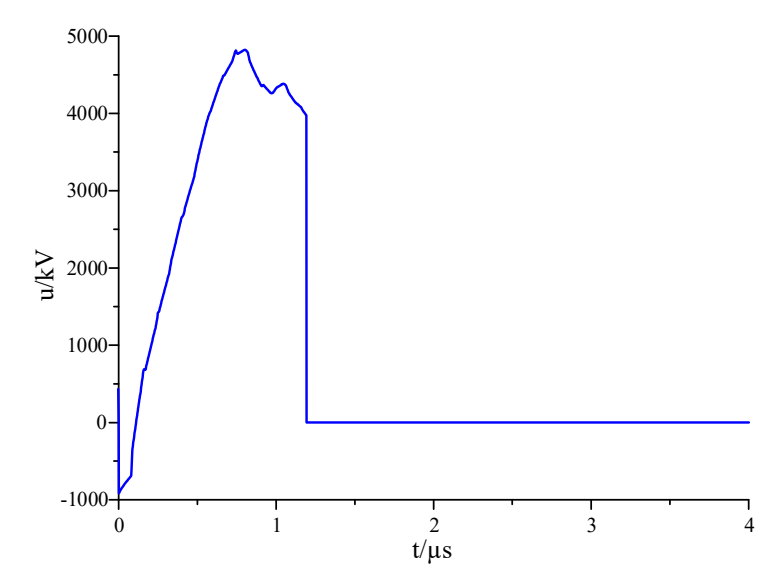

Figure 5. Voltage across the insulator (\#3 tower, single-phase back flashover at $177 \mathrm{kA}$ lightning current).

\subsubsection{Without the HCSR-FCL}

Table 7 shows the statistical calculation results of the maximum lightning overvoltage of the equipment in the station when the back flashover occurs on the incoming transmission lines. The maximum stress (voltage, current, energy) of the CVT arrester is $934 \mathrm{kV} / 6.33 \mathrm{kA} / 16 \mathrm{~kJ}$, which is within the rating value of the arrester.

Table 7. Voltage of the equipment.

\begin{tabular}{cccc}
\hline Tower Number & $\mathbf{C V T} / \mathbf{k V}$ & HGIS Bushing/kV & TR1/kV \\
\hline$\# 1$ & 1019 & 1186 & 968 \\
$\# 2$ & 998 & 1139 & 917 \\
$\# 3$ & 1140 & 1223 & 798 \\
$\# 4$ & 1060 & 1008 & 808 \\
$\# 5$ & 1048 & 990 & 800 \\
$\# 6$ & 943 & 1095 & 910 \\
\hline
\end{tabular}

\subsubsection{With the HCSR-FCL}

The configurations and equipment in the station are kept unchanged, and the lightning overvoltage of the HCSR-FCL under two working conditions of current limiting and current sharing are simulated and calculated respectively.

(1) The HCSR-FCL works in the current sharing state

Eight fast switches are closed when the HCSR-FCL works in the current sharing state, and the voltage-equalizing capacitor (C1) and the fast switching capacitor (C2 and C3) are approximately short-circuited to the ground. As a result, both arms of the HCSR coils can pass lightning current, and the lightning currents passed by the two arms are basically equal. Figure 6 shows the voltage of inter-terminal and inter-arm overvoltage of the HCSR during the back flashover of the transmission 
lines. Table 8 shows the overvoltage calculation results of each equipment in the station and the components of the HCSR.

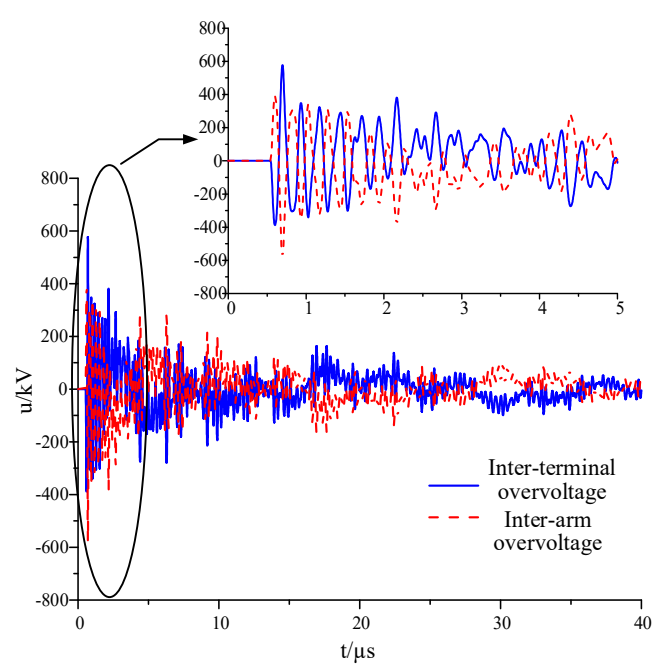

Figure 6. Inter-terminal and inter-arm overvoltage of the HCSR.

Table 8. Overvoltage of the equipment in current sharing state.

\begin{tabular}{ccccccc}
\hline \multirow{2}{*}{$\begin{array}{c}\text { Tower } \\
\text { Number }\end{array}$} & \multicolumn{2}{c}{ Station } & \multicolumn{4}{c}{ HCSR } \\
\cline { 2 - 7 } & $\mathbf{C V T / k V}$ & $\begin{array}{c}\text { HGIS } \\
\text { Bushing/kV }\end{array}$ & TR1/kV & $\begin{array}{c}\text { Inter-Terminal/ } \\
\mathbf{k V}\end{array}$ & $\begin{array}{c}\text { Inter-Arm/ } \\
\mathbf{~ k V}\end{array}$ & $\begin{array}{c}\text { Terminal-to- } \\
\text { Ground/kV }\end{array}$ \\
\hline$\# 1$ & 824 & 789 & 867 & 577 & 577 & 955 \\
$\# 2$ & 824 & 855 & 857 & 548 & 548 & 1045 \\
$\# 3$ & 788 & 863 & 810 & 537 & 537 & 1073 \\
$\# 4$ & 789 & 842 & 825 & 536 & 536 & 1008 \\
$\# 5$ & 787 & 755 & 833 & 536 & 536 & 1006 \\
$\# 6$ & 828 & 842 & 864 & 533 & 533 & 944 \\
\hline
\end{tabular}

Figure 6 shows that the inter-terminal and inter-arm overvoltage of HCSR is generally attenuated when the lightning overvoltage spreads to the HCSR. Table 8 shows that the maximum overvoltage of the equipment in the station is $867 \mathrm{kV}$, which is lower than the lightning impulse withstand voltage of the equipment considering a 1.25 times insulation margin [21]. The inter-terminal and inter-arm overvoltage of the HCSR is equal, and the maximum terminal-to-ground overvoltage of the HCSR is $1073 \mathrm{kV}$. The maximum stress of the arrester at the incoming terminal of the HCSR-FCL is $931 \mathrm{kV} / 6.051$ $\mathrm{kA} / 3 \mathrm{~kJ}$, which is within its rated values.

(2) The HCSR-FCL works in the current limiting state

When the HCSR-FCL works in the current limiting state, the eight fast switches are disconnected, and the voltage-equalizing capacitors are connected in series with one arm inductor. The topology of the HCSR-FCL circuit is changed, resulting in the different overvoltage between the inter-terminal and inter-arm overvoltage of the HCSR. Figure 7 shows the overvoltage simulation results when lightning strikes on tower \#3. Table 9 shows the overvoltage of each part of the equipment in the station and the components of the HCSR. 


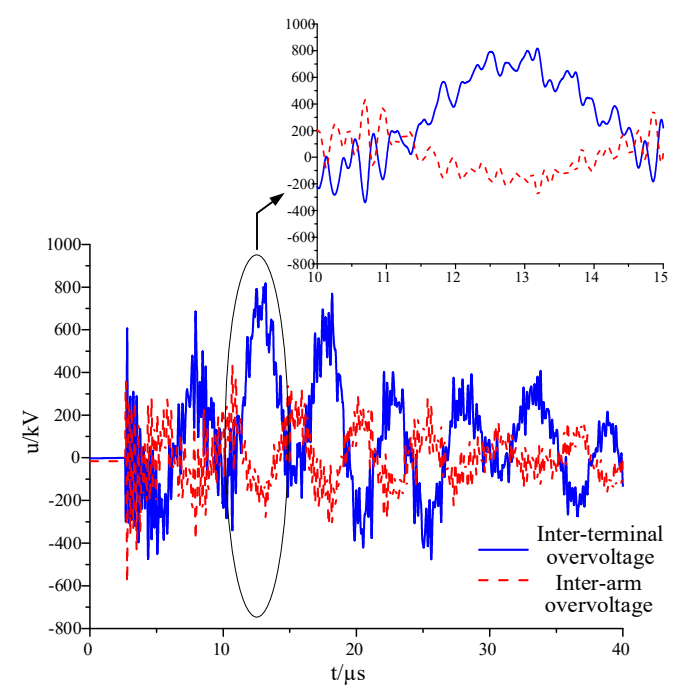

Figure 7. Inter-terminal and inter-arm overvoltage of the HCSR.

Table 9. Overvoltage of the equipment in current limiting state.

\begin{tabular}{ccccccc}
\hline \multirow{2}{*}{$\begin{array}{c}\text { Tower } \\
\text { Number }\end{array}$} & \multicolumn{2}{c}{ Station } & \multicolumn{3}{c}{ HCSR } \\
\cline { 2 - 7 } & $\mathbf{C V T / k V}$ & $\begin{array}{c}\text { HGIS } \\
\text { Bushing/kV }\end{array}$ & TR1/kV & $\begin{array}{c}\text { Inter-Terminal/ } \\
\mathbf{~ k V}\end{array}$ & $\begin{array}{c}\text { Inter-Arm/ } \\
\mathbf{~ k V}\end{array}$ & $\begin{array}{c}\text { Terminal-to- } \\
\text { Ground/ kV }\end{array}$ \\
\hline$\# 1$ & 630 & 640 & 696 & 657 & 629 & 1077 \\
$\# 2$ & 673 & 678 & 687 & 620 & 598 & 1239 \\
$\# 3$ & 787 & 755 & 660 & 817 & 586 & 1189 \\
$\# 4$ & 625 & 585 & 630 & 628 & 586 & 1063 \\
$\# 5$ & 628 & 587 & 649 & 821 & 586 & 1059 \\
$\# 6$ & 737 & 724 & 756 & 607 & 582 & 1030 \\
\hline
\end{tabular}

Figure 7 shows that the inter-terminal and inter-arm overvoltages of HCSR are different. The maximum inter-terminal voltage appears at $13 \mu$ s and then attenuates rapidly. The maximum inter-arm voltage appears at the initial moment of the lightning intrusion and attenuates rapidly. Table 9 shows that the maximum overvoltage of the equipment in the station is $787 \mathrm{kV}$, which is lower than the lightning impulse withstand voltage of the equipment. However, the maximum inter-terminal overvoltage, the maximum inter-arm overvoltage, and the maximum terminal-to-ground overvoltage of HCSR are up to $821 \mathrm{kV}, 629 \mathrm{kV}$, and $1239 \mathrm{kV}$, respectively, and the high voltage will increase the manufacturing difficulties for HCSRs. The maximum stress of the arrester at the incoming transmission lines side of the HCSR-FCL is $938 \mathrm{kV} / 6.769 \mathrm{kA} / 4 \mathrm{~kJ}$, which is within its protection level.

The above simulation results show that the maximum overvoltage of the equipment in the station is lower than the lightning impulse withstand voltage when the incoming transmission line is subjected to lightning back flashover, no matter if the HCSR-FCL is connected to the system or not. However, the inter-terminal overvoltage and inter-arm overvoltage of the HCSR are higher, i.e., $821 \mathrm{kV}$ and $629 \mathrm{kV}$, respectively. In order to reduce the design difficulty of the HCSR, it is necessary to take restraint measures to reduce the lightning overvoltage of the components in the HCSR and thus reduce the insulation requirements.

\subsection{Shielding Failure}

The maximum shielding failure current can be calculated by the electrical geometry model (EGM) of each tower on the incoming side of the station [17], and the lightning withstand level of each tower can be simulated and calculated. The calculation results are shown in Table 10. 
Table 10. The maximum shielding failure current and the lightning withstand level of each tower.

\begin{tabular}{ccc}
\hline Tower Number & $\begin{array}{c}\text { The Maximum Shielding } \\
\text { Failure Current/kA }\end{array}$ & $\begin{array}{c}\text { The Lightning Withstand } \\
\text { Level/kA }\end{array}$ \\
\hline$\# 1$ & 26 & 40 \\
$\# 2$ & 28 & 21 \\
$\# 3$ & 48 & 15 \\
$\# 4$ & 30 & 14 \\
$\# 5$ & 21 & 14 \\
$\# 6$ & 11 & 19 \\
\hline
\end{tabular}

When the lightning withstand level is greater than the maximum shielding failure current, the maximum shielding failure current is adopted in the simulation; otherwise, the maximum shielding failure current and the lightning withstand level are both adopted. The maximum overvoltage of each part of the equipment during lightning shielding failure on each tower are recorded and analyzed.

\subsubsection{Without the HCSR-FCL}

The maximum overvoltage of the equipment in the station is shown in Table 11, in which the lightning shielding failure occurs and the HCSR-FCL is not connected in the station.

Table 11. Simulation results of the maximum voltage on the equipment.

\begin{tabular}{ccccc}
\hline Tower Number & CVT/kV & $\begin{array}{c}\text { HGIS } \\
\text { Bushing/kV }\end{array}$ & TR1/kV & $\begin{array}{c}\text { Lightning Impulse } \\
\text { Withstand Voltage/kV }\end{array}$ \\
\hline$\# 1$ & 1110 & 1421 & 1107 & 1550 \\
$\# 2$ & 1222 & 1642 & 1109 & 1550 \\
$\# 3$ & 1275 & 1886 & 1091 & 1550 \\
$\# 4$ & 1130 & 1787 & 1093 & 1550 \\
$\# 5$ & 1046 & 1290 & 1053 & 1550 \\
$\# 6$ & 932 & 1010 & 955 & 1550 \\
\hline
\end{tabular}

Table 11 shows that the lightning overvoltage of some equipment exceeds the lightning impulse withstand voltage, and it is necessary to increase the arresters near the incoming transmission lines of the station to reduce the overvoltage. Therefore, two-column arresters are added to the CVT in the simulation, and Table 12 shows the maximum overvoltage of the equipment. The simulation results show that the overvoltage is apparently decreased, and the equipment can work in a safe condition.

Table 12. Maximum voltage of the equipment when the two-column arrester is added.

\begin{tabular}{ccccc}
\hline Tower Number & CVT/kV & $\begin{array}{c}\text { HGIS } \\
\text { Bushing/kV }\end{array}$ & TR1/kV & $\begin{array}{c}\text { Lightning Impulse } \\
\text { Withstand Voltage/kV }\end{array}$ \\
\hline$\# 1$ & 1002 & 1127 & 983 & 1550 \\
$\# 2$ & 1007 & 1119 & 983 & 1550 \\
$\# 3$ & 1049 & 1152 & 947 & 1550 \\
$\# 4$ & 1009 & 1235 & 938 & 1550 \\
$\# 5$ & 1034 & 1091 & 942 & 1550 \\
$\# 6$ & 904 & 973 & 874 & 1550 \\
\hline
\end{tabular}

\subsubsection{With the HCSR-FCL}

(1) The HCSR-FCL works in the current sharing state

The overvoltage of the HCSR is shown in Figure 8 when the $48 \mathrm{kA}$ lightning current strikes on the transmission line near tower \#3. Figure 8 shows that the maximum inter-terminal and inter-arm overvoltages of the HCSR appear at $9 \mu \mathrm{s}$, and the overvoltage is generally attenuated. Table 13 shows the detailed simulation results. 


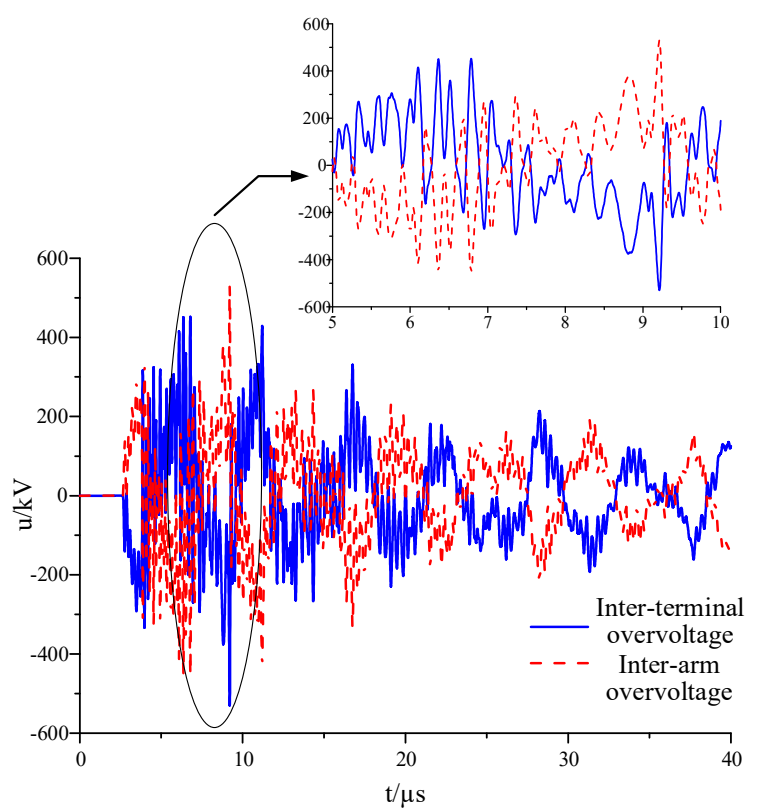

Figure 8. Inter-terminal and inter-arm overvoltage of the HCSR.

Table 13. Overvoltage of the equipment in current sharing state.

\begin{tabular}{ccccccc}
\hline \multirow{2}{*}{$\begin{array}{c}\text { Tower } \\
\text { Number }\end{array}$} & \multicolumn{2}{c}{ Station } & \multicolumn{3}{c}{ HCSR } \\
\cline { 2 - 7 } & $\mathbf{C V T / k V}$ & $\begin{array}{c}\text { HGIS } \\
\text { Bushing/kV }\end{array}$ & TR1/kV & $\begin{array}{c}\text { Inter-Terminal/ } \\
\mathbf{k V}\end{array}$ & $\begin{array}{c}\text { Inter-Arm/ } \\
\mathbf{~ k V}\end{array}$ & $\begin{array}{c}\text { Terminal-to- } \\
\text { Ground/kV }\end{array}$ \\
\hline$\# 1$ & 935 & 1030 & 901 & 198 & 198 & 1129 \\
$\# 2$ & 915 & 971 & 896 & 420 & 420 & 1280 \\
$\# 3$ & 921 & 949 & 895 & 530 & 530 & 1343 \\
$\# 4$ & 898 & 930 & 895 & 623 & 623 & 1157 \\
$\# 5$ & 912 & 925 & 896 & 627 & 627 & 1040 \\
$\# 6$ & 884 & 890 & 894 & 119 & 119 & 984 \\
\hline
\end{tabular}

Table 13 shows that the maximum overvoltage of the equipment in the station is $1030 \mathrm{kV}$, which is lower than the insulation level of the equipment. However, both the maximum inter-terminal overvoltage of the HCSR and the maximum inter-arm overvoltage of the HCSR are $627 \mathrm{kV}$, and the maximum terminal-to-ground overvoltage of the HCSR is $1343 \mathrm{kV}$. The maximum stress of the arrester near the incoming transmission line side of the HCSR-FCL is $1075 \mathrm{kV} / 26.756 \mathrm{kA} / 28 \mathrm{~kJ}$, which is beyond its rated values. Hence, further lightning protection measures are needed.

(2) The HCSR-FCL works in the current limiting state

Figure 9 shows the inter-terminal and inter-arm overvoltages of the HCSR when the lightning current with an amplitude of $21 \mathrm{kA}$ strikes on the conductor of tower \#5. Figure 9 shows that the maximum inter-terminal overvoltages of the HCSR appears at $22 \mu \mathrm{s}$ and the maximum inter-arm voltage appears at $8 \mu \mathrm{s}$ when the lightning overvoltage spreads to the HCSR. This is due to the different topology of the two arms of the HCSR. The voltage-equalizing capacitors and stray capacitors to the ground of the fast switches in the current limiting state affect the high frequency transient process of lightning current spreading to the HCSR. Table 14 shows the lightning overvoltage of each part of the equipment in the station and the components of the HCSR. 


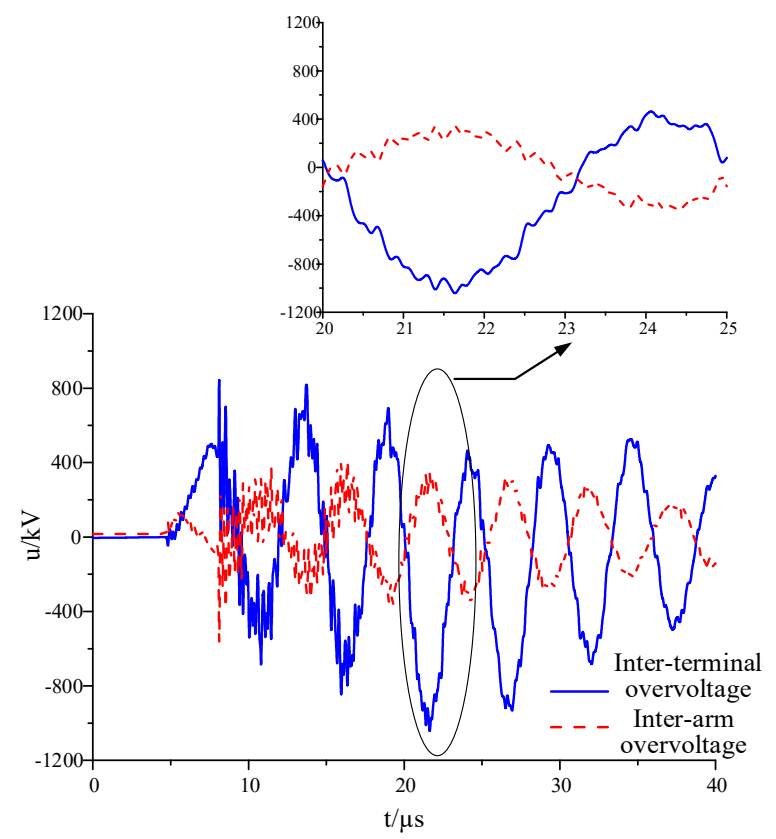

Figure 9. Inter-terminal and inter-arm overvoltage of the HCSR.

Table 14. Overvoltage of the equipment in current limiting state.

\begin{tabular}{ccccccc}
\hline \multirow{2}{*}{$\begin{array}{c}\text { Tower } \\
\text { Number }\end{array}$} & \multicolumn{2}{c}{ Station } & \multicolumn{4}{c}{ HCSR } \\
\cline { 2 - 7 } & $\mathbf{C V T / k V}$ & $\begin{array}{c}\text { HGIS } \\
\text { Bushing/kV }\end{array}$ & TR1/kV & $\begin{array}{c}\text { Inter-Terminal/ } \\
\mathbf{k V}\end{array}$ & $\begin{array}{c}\text { Inter-Arm/ } \\
\mathbf{~ k V}\end{array}$ & $\begin{array}{c}\text { Terminal-to- } \\
\text { Ground/kV }\end{array}$ \\
\hline$\# 1$ & 844 & 885 & 804 & 556 & 197 & 1227 \\
$\# 2$ & 760 & 777 & 760 & 928 & 543 & 1247 \\
$\# 3$ & 845 & 862 & 788 & 914 & 712 & 1475 \\
$\# 4$ & 815 & 853 & 787 & 1064 & 633 & 1262 \\
$\# 5$ & 901 & 853 & 787 & 1041 & 567 & 1253 \\
$\# 6$ & 810 & 837 & 783 & 413 & 126 & 993 \\
\hline
\end{tabular}

Table 14 shows that the maximum overvoltage of the equipment in the station is $901 \mathrm{kV}$, which is lower than the lightning impulse withstand voltage of the equipment. However, the maximum inter-terminal overvoltage, the maximum inter-arm overvoltage, and the maximum terminal-to-ground overvoltage of HCSR are up to $1064 \mathrm{kV}, 712 \mathrm{kV}$, and $1475 \mathrm{kV}$ respectively. The maximum stress of the arrester near the incoming side of the HCSR-FCL is $1075 \mathrm{kV} / 26.756 \mathrm{kA} / 28 \mathrm{~kJ}$, which is beyond its rated values. So further lightning protection measures are needed.

The above simulation results show that the maximum overvoltage of the equipment in the station is lower than the lightning impulse withstand voltage when the incoming transmission line is subjected to lightning shielding failure, no matter if the HCSR-FCL is connected to the system or not. However, the inter-terminal and inter-arm overvoltage of the HCSR is very high, and the maximum stress of the arrester near the incoming side of the HCSR-FCL is beyond its rated value. In order to reduce the design difficulty of the HCSR and the residual voltage of the arrester, it is necessary to take effective measures to reduce the lightning overvoltage and thus reduce the insulation requirements.

\section{Protection Measures and the Lightning Impulse Withstand Overvoltage of HCSR-FCL}

The above simulation analysis shows that the lightning overvoltage of equipment in the station under shielding failure is more serious than that under back flashover of the incoming transmission lines, and the maximum stress of the arrester near the incoming side of the HCSR-FCL is beyond its rated value. 
This section studies lightning overvoltage protection measures for the HCSR-FCL. Based on the lightning overvoltage protection measures for the FCLs, such as adding an arrester across the FCL, adding a ground capacitor in the terminals of the FCL, adding a shunt capacitor across of the FCL, etc. [26-28], three protection measures for the HCSR-FCL are proposed and shown in Figures 10-12. When the capacitor takes $1200 \mathrm{nF}$, the maximum inter-terminal and inter-arm overvoltage of the HCSR in the first protection measures are $512 \mathrm{kV}$ and $205 \mathrm{kV}$, the maximum inter-terminal and inter-arm overvoltage of the HCSR in the second protection measures are $354 \mathrm{kV}$ and $185 \mathrm{kV}$, and the maximum inter-terminal and inter-arm overvoltage of the HCSR in the third protection measures are $123 \mathrm{kV}$ and $147 \mathrm{kV}$. Comparing the three protection measures, the overvoltage of the third protection measure shown in Figure 12 is much lower. Therefore, the third protection measures are proposed. The proposed protection measures include increasing the two-column arrester MOA2 on the incoming side and adding a shunt capacitor $\mathrm{C} 4$ across each module of HCSR at the same time. The topology of the HCSR-FCL with the proposed protection measures is shown in Figure 12, and the simulation results under these measures are shown in Tables 15 and 16.

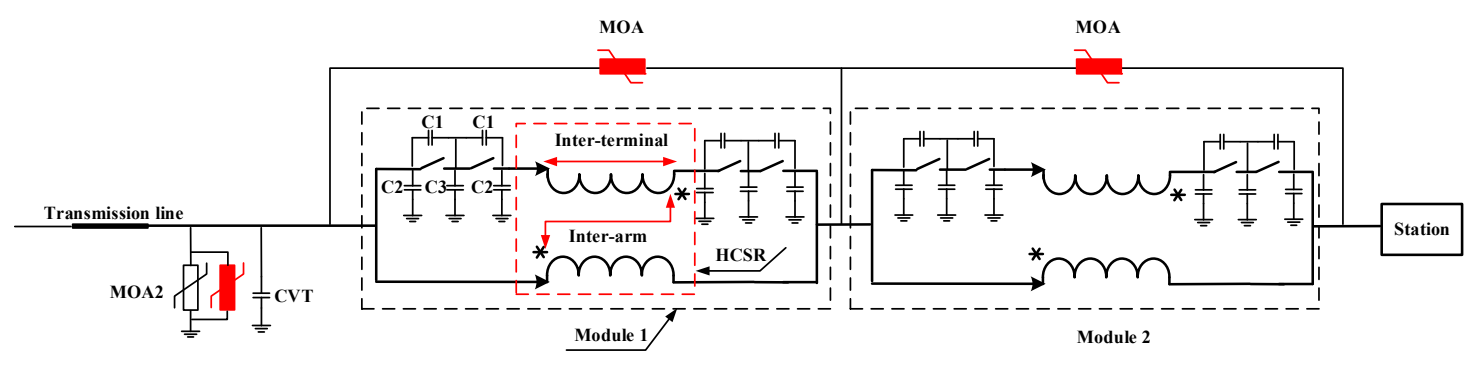

Figure 10. The topology of the HCSR-FCL with the first protection measures.

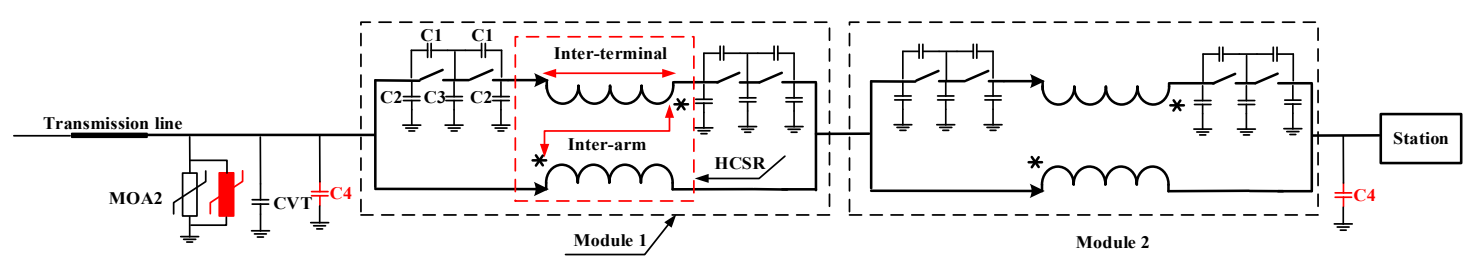

Figure 11. The topology of the HCSR-FCL with the second protection measures.

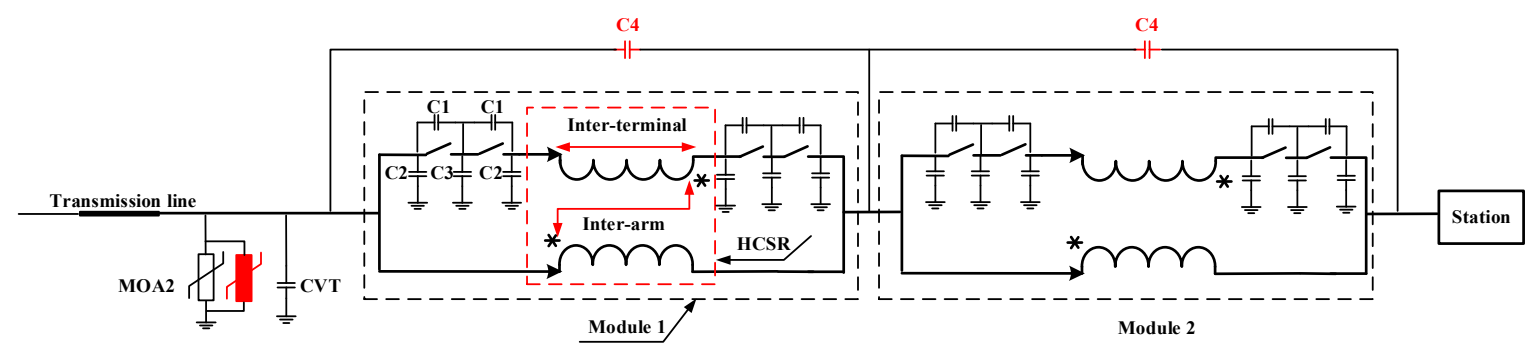

Figure 12. The topology of the HCSR-FCL with the third protection measures.

After two modules of the HCSR-FCL are both connected with a same shunt capacitor (C4), the equivalent impedance of the shunt capacitor is much lower. Therefore, most lightning current flows from the shunt capacitor, so the amplitude and steepness of the lightning current flowing through the HCSR decrease, resulting in reducing the amplitude and steepness of the inter-terminal and inter-arm overvoltage of HCSR greatly. Table 15 shows the lightning overvoltage of the equipment in the station when the HCSR-FCL is working in current sharing state, and Table 16 shows the lightning overvoltage when the HCSR-FCL is working in current limiting state. 
Table 15. Maximum overvoltage of the equipment with the HCSR-FCL working in current sharing state.

\begin{tabular}{ccccccc}
\hline \multirow{2}{*}{$\begin{array}{c}\text { Shunt } \\
\text { Capacitor/nF }\end{array}$} & \multicolumn{2}{c}{ Station } & \multicolumn{3}{c}{ HCSR } \\
\cline { 2 - 7 } & $\mathbf{C V T / k V}$ & $\begin{array}{c}\text { HGIS } \\
\text { Bushing/kV }\end{array}$ & TR1/kV & $\begin{array}{c}\text { Inter-Terminal/ } \\
\mathbf{~ k V}\end{array}$ & $\begin{array}{c}\text { Inter-Arm/ } \\
\mathbf{~ k V}\end{array}$ & $\begin{array}{c}\text { Terminal-to- } \\
\text { Ground/kV }\end{array}$ \\
\hline 400 & 1080 & 1120 & 956 & 99 & 99 & 1171 \\
800 & 1081 & 1133 & 960 & 93 & 93 & 1168 \\
1200 & 1079 & 1136 & 961 & 72 & 72 & 1163 \\
\hline
\end{tabular}

Table 16. Maximum overvoltage of the equipment with the HCSR-FCL working in current limiting state.

\begin{tabular}{ccccccc}
\hline \multirow{2}{*}{$\begin{array}{c}\text { Shunt } \\
\text { Capacitor/nF }\end{array}$} & \multicolumn{2}{c}{ Station } & \multicolumn{3}{c}{ HCSR } \\
\cline { 2 - 7 } & $\mathbf{C V T / k V}$ & $\begin{array}{c}\text { HGIS } \\
\text { Bushing/kV }\end{array}$ & TR1/kV & $\begin{array}{c}\text { Inter-Terminal/ } \\
\mathbf{~ k V}\end{array}$ & $\begin{array}{c}\text { Inter-Arm/ } \\
\mathbf{~ k V}\end{array}$ & $\begin{array}{c}\text { Terminal-to- } \\
\text { Ground/kV }\end{array}$ \\
\hline 400 & 1074 & 1131 & 959 & 151 & 157 & 1170 \\
800 & 1082 & 1127 & 961 & 129 & 151 & 1156 \\
1200 & 1082 & 1127 & 962 & 123 & 147 & 1164 \\
\hline
\end{tabular}

Comparing Tables 13 and 14 to Tables 15 and 16, it can be seen that the overvoltage of the equipment in the station increases to some extent. This is because the lightning current that flows into the station increases by passing the shunt capacitors, but the lightning overvoltage is still lower than the lightning impulse withstand voltage of the equipment in the station. However, the inter-terminal and inter-arm overvoltage of the HCSR decreases greatly, and the larger the shunt capacitor, the smaller the lightning overvoltage between terminals and arms of HCSR.

In summary, after adding two-column arresters and two shunt capacitors, the overvoltage of the equipment in the station and the HCSR are both decreased to reasonable values. The lightning impulse withstand voltage of each component of HCSR is also proposed, that is, the inter-terminal lightning impulse withstand voltage of HCSR is $170 \mathrm{kV}$, the inter-arm lightning impulse withstand voltage of HCSR is $200 \mathrm{kV}$, and the terminal-to-ground lightning impulse withstand voltage of HCSR is $1550 \mathrm{kV}$.

\section{Conclusions}

In this paper, the lightning intruding overvoltage of a $500 \mathrm{kV}$ AC power station with or without an HCSR-FCL is simulated and analyzed, and the lightning protection measures of the HCSR-FCL and lightning impulse withstand voltage of the HCSR are proposed. The main conclusions are as follows:

(1) The simulation model of the lightning intruding overvoltage of the $500 \mathrm{kV}$ AC station with or without an HCSR-FCL is established.

(2) The simulation results show that the lightning overvoltage of the equipment in the station is decreased by connecting an HCSR-FCL, but the overvoltage of the HCSR-FCL is very high because of the high impedance of the HCSR, and the inter-arm and inter-terminal voltages also need to be decreased. The lightning intruding overvoltage is higher in shielding failure than the back flashover of the incoming transmission lines.

(3) The inter-terminal overvoltage of the HCSR is the same as the inter-arm overvoltage of the HCSR when it works in the current sharing state, while the inter-terminal overvoltage of the HCSR is lower than the inter-arm overvoltage of the HCSR when it works in the current limiting state.

(4) Protection measures of adding arresters and shunt capacitors are proposed, and the simulation results show that the measures are effective. Moreover, it is proposed that each shunt capacitor is $1200 \mathrm{nF}$, the inter-terminal lightning impulse withstand voltage of the HCSR is $170 \mathrm{kV}$, the inter-arm lightning impulse withstand voltage of the HCSR is $200 \mathrm{kV}$, and the terminal-to-ground lightning impulse withstand voltage of the HCSR is $1550 \mathrm{kV}$. 
(5) The high frequency equivalent models of the equipment in the station are classical, but the high frequency equivalent model of the HCSR-FCL is unique, and it will be validated by the lighting impulse experiments after the HCSR-FCL is constructed.

Author Contributions: Conceptualization, Y.H. and C.C.; Methodology, Y.H. and C.C.; Software, C.C. and K.W.; Validation, J.H., K.W. and Z.Y.; Formal analysis, J.H.; Investigation, C.C. and J.H.; Resources, C.C.; Data curation, J.H.; Writing—original draft preparation, C.C.; Writing—review and editing, Y.H.; Visualization, C.C.; Supervision, Y.H. and Z.Y.; Project administration, Y.H. and J.L.; Funding acquisition, Y.H., J.L., W.M., H.S. and X.Z.

Funding: This research and APC were funded by the National Key R\&D Program of China, grant number 2018YFB0904300, and the Science and Technology Project of China Southern Power Grid Co., Ltd., grant number GZHKJXM20180055.

Conflicts of Interest: The authors declare no conflict of interest.

\section{Abbreviations}

$\begin{array}{ll}\text { HCSR } & \text { High Coupled Split Reactor } \\ \text { HCSR-FCL } & \text { Fault Current Limiter based on High Coupled Split Reactor } \\ \text { TR } & \text { Transformer } \\ \text { CVT } & \text { Capacitive Voltage Transformer } \\ \text { HGIS } & \text { Hybrid Gas Insulated Switchgear } \\ \text { DS } & \text { Disconnector } \\ \text { CT } & \text { Current Transformer } \\ \text { CB } & \text { Circuit Breaker } \\ \text { MOA } & \text { Metal Oxide Arrester } \\ \text { GFD } & \text { Ground Flash Density } \\ \text { OHGW } & \text { Overhead Ground Wire }\end{array}$

\section{Appendix A}

When a station needs to install the HCSR-FCL, the lightning overvoltage of the HCSR-FCL can be calculated by using the method shown in Figure A1. 


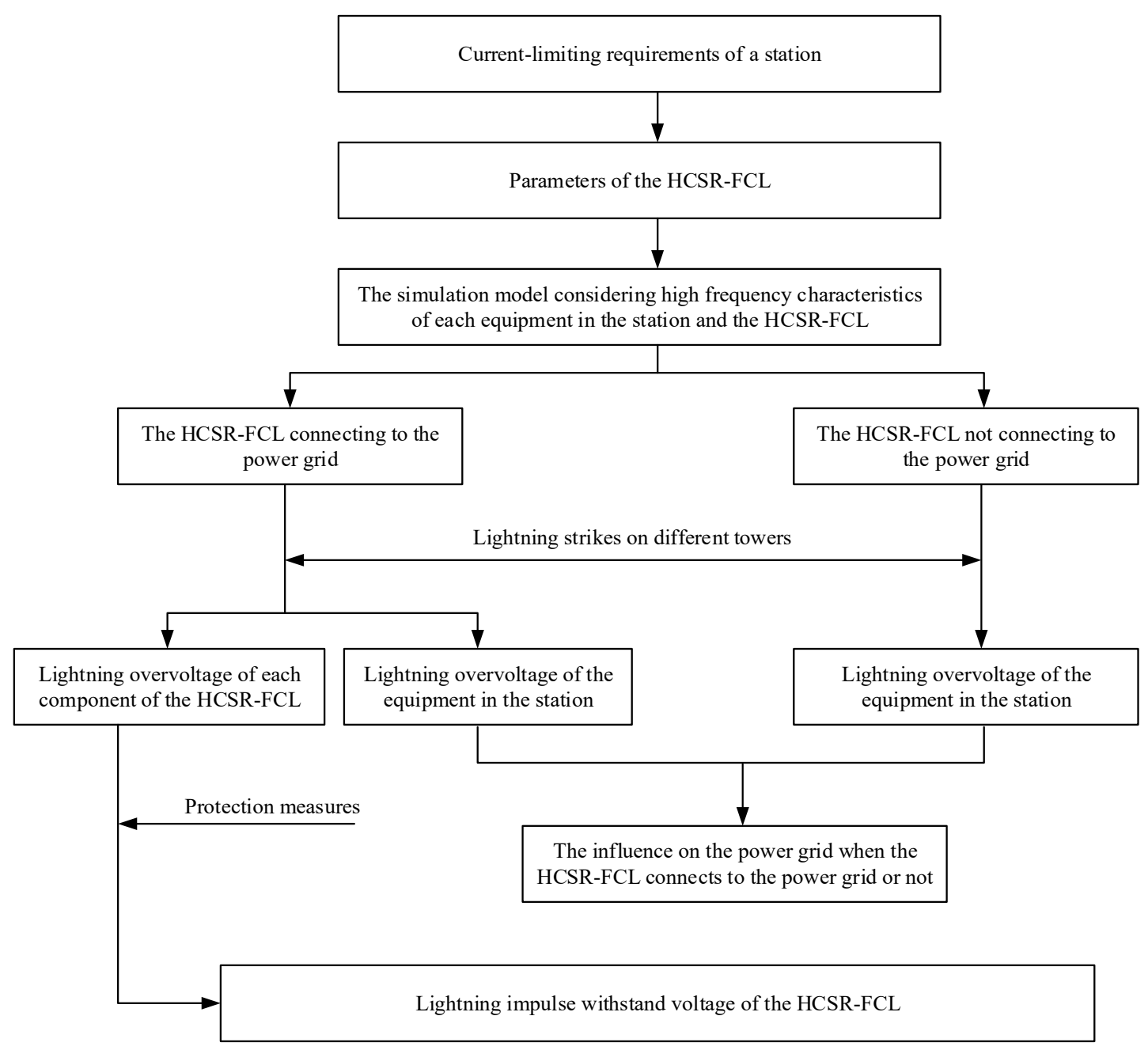

Figure A1. The flow chart of the method how to study the lightning overvoltage and insulation design of the HCSR-FCL.

\section{References}

1. Qi, S.; Ze, C.; Ai, L.; Li, L.; Ke, W. A Short-circuit Current Over-limited Mechanism of 500 kV Power System and the Adaptability of Limiting Measures. High Volt. Eng. 2009, 33, 92-96.

2. Liao, G.; Xie, X.; Hou, Y.; Li, M. Analysis on the problems of three-phase short-circuit current over-limited of $500 \mathrm{kV}$ bus when UHV connected to Hunan power grid. High Volt. Eng. 2015, 41, 747-753.

3. Yong, W.; Xin, L.; Hai, S.; Jun, L.; De, Q.; Ze, G. Interrupting Process Simulation of HCSR Based 252 kV, 85 kA Large Capacity Short-Circuit Current Breaking Device. South. Power Syst. Technol. 2017, 11, 35-39.

4. Yang, Q.; Blond, S.L.; Liang, F.; Wei, Y.; Min, Z.; Jian, L. Design and Application of Superconducting Fault Current Limiter in a Multiterminal HVDC System. IEEE Trans. Appl. Supercond. 2017, 27, 1-5. [CrossRef]

5. Qing, L.; Qing, Q.; Zhi, Z.; Nai, S.; Li, J.; Dong, H. AC/DC Current Limiting Characteristics of the Divisive Reactance Type Superconducting Fault Current Limiter. High Volt. Eng. 2018, 44, 456-462.

6. Hobl, A.; Goldacker, W.; Dutoit, B.; Martini, L.; Petermann, A.; Tixador, P. Design and Production of the ECCOFLOW Resistive Fault Current Limiter. IEEE Trans. Appl. Supercond. 2013, 23. [CrossRef]

7. Qing, Q.; Li, X.; Zhi, Z.; Zhi, G.; Li, J. Investigation of Double-Splitting Iron Reactor Used in Resonant Type Fault Current Limiter. Trans. China Electrotech. Soc. 2017, 32, 164-171.

8. Didier, G.; Bonnard, C.H.; Douine, B.; Leveque, J. Power system stability improvement with superconducting fault current limiter. In Proceedings of the International Conference on Electrical Sciences \& Technologies in Maghreb, Tunis, Tunisia, 3-6 November 2016. 
9. Naderi, S.B.; Jafari, M.; Tarafdar, H.M. Parallel-Resonance-Type Fault Current Limiter. IEEE Trans. Ind. Electron. 2013, 60, 2538-2546. [CrossRef]

10. Zhao, Y.; Xiao, Y.; Yuan, P.; Jun, H. Current dividing process of paralleled circuit breakers with high coupled split reactor. High Volt. Eng. 2012, 38, 2008-2014.

11. Zhao, Y.; Jun, H.; Yuan, P.; Xiao, Y.; Chu, L.; Si, C. Research on electromagnetic efficiency optimization in the design of air-core coils. Int. Trans. Electr. Energy Syst. 2015, 25, 789-798.

12. Fa, Y.; Bo, T.; Can, D.; Shi, Q.; Li, H.; Zhao, Y. Optimization Design of a High-Coupling Split Reactor in a Parallel-Type Circuit Breaker. IEEE Access 2019, 7, 33473-33480.

13. Kai, W.; Zhao, Y.; Jun, H. The analyses of current transfer process of parallel generator circuit breakers with high coupled split reactor. Proceedings of the 21st International Conference on Gas Discharges and their Applications in Nagoya. IEEJ 2016, 16, 271-275.

14. Yan, D.; Xuan, C.; Fei, L.; Ting, Y. Design of Coupled Reactors Used for Parallel Circuit Breakers. High Volt. Eng. 2009, 35, 2870-2875.

15. Hai, S.; Ze, G.; Wen, M.; Xing, L.; Yong, W.; Jian, Y. Influence of Paralleled Capacitor on Paralleled High-voltage SF6 Circuit Breakers with Highly Coupled Split Reactor. High Volt. Eng. 2017, 43, 866-871.

16. De, Y.; Rong, C.; Jie, W.; Feng, W.; Jun, L.; Yong, W. Development of High Coupled Split Reactor for Large Capacity Parallel Circuit Breaker Device. Transformer 2017, 54, 25-32.

17. GB/T50064-2014. Code for Design of Overvoltage Protection and Insulation Coordination for AC Electrical Devices[S]; China Planning Press: Beijing, China, 2014.

18. The Institute of Electrical and Electronics Engineers, Inc. IEEE Std 1243-1997 IEEE Guide for Improving the Lightning Performance of Transmission Lines; The Institute of Electrical and Electronics Engineers, Inc.: New York, NY, USA, 1997.

19. Yamada, T.; Mochizuki, A.; Sawada, J.; Zaima, E.; Kawamura, T.; Ametani, A.; Ishii, M.; Kato, S. Experimental evaluation of a UHV tower model for lightning surge analysis. IEEE Trans. Power Deliv. 1995, 10, $393-402$. [CrossRef]

20. Hara, Y. Modelling of a transmission tower for lightning-surge analysis. Genera. Transm. Distrib. IEE Proc. 1996, 143, 283-289. [CrossRef]

21. CIGRE Working Group 01 of SC 33. Guide to Procedures for Estimating the Lightning Performance of Transmission Lines; CIGRE Brochure: Paris, France, 1991; p. 171.

22. Yu, L.; Wei, L.; Xian, C. Research on Lightning Intruded Wave for $500 \mathrm{kV}$ Substations. J. Chongqin Univ. 2000, 23, 17-19.

23. Zhao, Y.; Hong, Z. Calculation and Study of Lightning Intruding Surge for 500kV HGIS Substation. High Volt. Eng. 2007, 33, 71-75.

24. Chuan, Z.; Nian, L.; Bing, T.; Dong, C.; Kun, L. Lightning overvoltage calculation based on Bergeron model for $500 \mathrm{kV}$ substation. Electr. Power Autom. Equip. 2010, 30, 66-69.

25. Yong, H.; Jie, Z.; Yu, Z.; Guo, L.; Qiu, H.; Li, L. Simulation on the Lightning Intruding Overvoltage of the 10kV DC Distribution Network Based on VSC-DC. High Volt. Eng. 2018, 44, 2533-2540.

26. Shirai, Y.; Miyato, Y.; Taguchi, M.; Shiotsu, M.; Hatta, H.; Muroya, S.; Chiba, M.; Nitta, T. Over-voltage Suppression in a Fault Current Limiter by a Zno Varistor. IEEE Trans. Appl. Supercond. 2003, 13, $2064-2067$. [CrossRef]

27. Qiu, S.; Fang, W.; Jian, Y.; Zhi, Z.; Tian, X. Study on Lightning Intruding Overvoltage Characteristics of Current Limiting Reactors in Jiangsu 500kV Power Grid. Acad. Annu. Meet. High Volt. Prof. Comm. China Electr. Eng. Soc. 2015, 23, 1-6.

28. Yi, H.; Chang, L.; Ai, W.; Xin, Y. Experimental of Over-voltage Suppression in a HTS Three-phase Saturated Core Fault Current Limiter by a ZnO Varistor. High Volt. Eng. 2007, 33, 154-158.

(C) 2019 by the authors. Licensee MDPI, Basel, Switzerland. This article is an open access article distributed under the terms and conditions of the Creative Commons Attribution (CC BY) license (http://creativecommons.org/licenses/by/4.0/). 